\title{
Esophageal Small Cell Carcinoma with Synchronous Renal Cell Carcinoma: A Case Report with Review of the Literature
}

\author{
Parakkal Deepak $^{a}$ Radha Devi ${ }^{b}$ Harikrishnan Pillai ${ }^{c}$ \\ aUniversity of Chicago (North Shore University Health System) and bUniversity of \\ Illinois at Chicago (St Francis Hospital), Evanston, III., USA; 'Academy of Medical \\ Sciences, Kannur, India
}

\section{Key Words}

Small cell carcinoma Esophagus · Synchronous malignancies $\cdot$ Renal cell carcinoma

\begin{abstract}
Synchronous malignancies with an esophageal malignancy are not uncommon. However synchronous esophageal and renal cell carcinoma (RCC) is rare with only 11 cases reported in the world literature, the esophageal malignancies being adenocarcinomas or squamous cell carcinomas. Here, we report the first case of synchronous small cell carcinoma (SCC) of the esophagus with a RCC. SCC of the esophagus is an aggressive malignancy with poor prognosis constituting $0.8-2.4 \%$ of all esophageal malignancies, currently treated with induction chemotherapy followed by chemoradiotherapy. Our patient underwent chemoradiotherapy for the SCC of the esophagus followed by radical nephrectomy for the RCC. He developed metastatic disease and died 8 months after diagnosis. Larger case series are required to develop a treatment algorithm for such a rare presentation. The key points of this report are: (1) Synchronous RCC with a primary esophageal carcinoma is a rare presentation. (2) This is the first described case report of a SCC of the esophagus with a synchronous RCC. (3) Overall prognosis in a synchronous presentation is determined by the primary esophageal malignancy. (4) Esophageal carcinomas with synchronous malignancies have a poorer prognosis compared to isolated esophageal carcinoma.
\end{abstract}

\section{Introduction}

The occurrence of synchronous malignancies with an esophageal malignancy is a well-described phenomenon with an incidence ranging from 3.6 to $27.1 \%$, most commonly situated in the upper aero-digestive tract [1]. In world literature, only 11 cases of synchronous esophageal and renal cell carcinoma (RCC) have been previously 
described [1-5], the esophageal malignancies being histologic subtype of adenocarcinoma or squamous cell carcinoma. Identifying a synchronous RCC is important as this may affect the selection of the treatment approach. Radical nephrectomy for the RCC may also result in renal dysfunction limiting the chemotherapeutic options for the esophageal malignancy. We report the first case of a small cell carcinoma (SCC) of the esophagus with synchronous RCC along with a review of treatment modalities based on the available literature for synchronous presentation.

\section{Case Report}

A 61-year-old Hispanic male with a 25 pack year history of smoking presented with a history of difficulty in swallowing for both solids and liquids of 2 weeks duration with a 3-day history of food getting stuck in his throat on swallowing and having to vomit it up.

Esophagogastroduodenoscopy demonstrated a 10-cm-long tumor in the esophagus starting $35 \mathrm{~cm}$ from the upper incisor (fig. 1) and extending down to the gastric cardia. Metastatic work-up with a computed tomography (CT) scan of the chest, abdomen and pelvis revealed a heterogeneous mass in the region of the gastric fundus and gastroesophageal junction with enlarged perigastric lymph nodes along the lesser curvature nodes. Another heterogeneous enhancing, lobulated mass measuring $5.2 \times 4.4 \mathrm{~cm}$ was seen involving the lower pole anterior cortex of the right kidney with mild perirenal extension. Biopsy of the esophageal mass revealed a SCC of the esophagus (fig. 2), with positive staining for synaptophysin and vimentin and negative for chromogranin, cytokeratin, leucocyte common antigen and S-100. The esophageal SCC was differentiated from a lung primary based on negative staining for thyroid transcription factor-1. A CT-guided biopsy of the renal mass revealed a primary RCC of clear and granular cell type, grade 2-3 (fig. 3). The patient underwent further metastatic work-up with a bone scan and a CT of the head which showed no evidence of distant metastasis.

He underwent concomitant chemoradiotherapy for his esophageal cancer with four cycles of 5-fluorouracil and cisplatin along with $50 \mathrm{~Gy}$ of radiotherapy in fractionated doses and esophageal stent placement to relieve dysphagia. He then underwent six cycles of chemotherapy with carboplatin and etoposide followed by right radical nephrectomy revealing a T3aNxMx grade 3 clear cell type RCC with capsular extension but with negative surgical margins. On follow-up CT scan of the abdomen and pelvis 8 months after the initial diagnosis, multiple soft tissue nodules in the right renal fossa suspicious for metastatic disease were seen along with an anterior abdominal wall nodule, enlargement of the psoas muscle and periaortic lymphadenopathy. Biopsy of the abdominal wall nodule revealed metastatic SCC. His chemotherapy regimen was changed to pemetrexed, but given the extent of metastatic disease and after discussion with the patient and his family, he was transferred to hospice care where he subsequently died.

\section{Discussion}

Malignant tumors of the esophagus or gastroesophageal junction and RCC are both malignancies which are relatively frequent. Synchronous malignancies have been described with an esophageal malignancy ranging up to 27.1\% [1]. An exhaustive review of the literature using PubMed (www.ncbi.nlm.nih.gov/pubmed) identified 11 reports [1-5] of synchronous esophageal and renal malignancies. Since the advent of CT scanning as part of the metastatic work-up of esophageal malignancy, De Hingh et al. [1] have described a $2.1 \%$ ( 4 out of 192) incidence of synchronous RCC in patients operated on for esophageal malignancy. Previous to this, individual case reports of 4 cases of esophageal malignancy with synchronous RCC have been reported [2-4]. Three more cases of esophageal malignancy with synchronous RCC were identified in a retrospective study of 744 patients conducted between 1985 and 1998 by Kumagai et al. [5]. In all these cases, the primary malignancy was of adenocarcinoma or squamous cell subtype. Our 
study is the first one to describe a case of SCC of the esophagus with a synchronous primary RCC.

SCC of the esophagus is a rare and aggressive malignancy with as few as approximately 450 cases reported in the world literature [6,7], with an incidence of $0.8-2.4 \%$ of all esophageal malignancies. The median survival for patients with limited disease is around 22.3 months (range 6 months to $11.2+$ years) and for patients with extensive disease it is around 8.5 months (range 1.5 months to 2.2 years) [6]. Currently its pathology and treatment is extrapolated from pulmonary SCC. Recent series [6] have demonstrated the superiority of using induction chemotherapy followed by chemoradiotherapy without surgery in achieving long-term survival, unlike earlier series which advocated a surgical approach to SCC. Early metastasis is common with SCC, most commonly to the periesophageal and mediastinal lymph nodes and to the liver with very poor prognosis and a $10 \%$ one-year survival.

In esophageal cancers associated with other primary cancers, the prognosis is primarily determined by the esophageal cancer itself with 5-year survival rates significantly worse than those of patients with solitary esophageal cancer [5]. It is also important to differentiate a renal metastasis from a primary RCC to determine a surgical approach for the renal mass. The synchronous occurrence of an esophageal malignancy and an RCC could be due to an ingested carcinogen which is excreted by the kidney, exposing both the esophagus and the kidney to the carcinogen. Tobacco smoke could be the potential carcinogen in our case as the patient had a 25 pack year history of smoking, previously known to increase the risk of both extrapulmonary SCCs [8] and renal cancers [9].

Previous case series have advocated a simultaneous surgical resection of the esophageal malignancy along with the RCC, alternatively to treat the esophageal malignancy first followed by delayed treatment of a small RCC [1].

Our patient's esophageal malignancy was of a highly aggressive histological subtype with poor prognosis. The approach was chemoradiotherapy for the SCC of the esophagus followed by surgical approach for the RCC. Larger case series are required to determine a treatment algorithm for a similar presentation of SCC of the esophagus with synchronous RCC.

\section{Disclosure Statement}

There is no conflict of interest for any of the authors or co-authors of this paper. This paper did not receive any funding. 


\begin{tabular}{c|l|l|l}
$\begin{array}{c}\text { Case Reports in } \\
\text { Gastroenterology }\end{array}$ & $\begin{array}{l}\text { Case Rep Gastroenterol 2011;5:196-200 } \\
\text { DOl: 10.1159/000326958 }\end{array}$ & $\begin{array}{l}\text { Published online: } \\
\text { April 13, 2011 }\end{array}$ & $\begin{array}{l}\text { O 2 2011 S. Karger AG, Basel } \\
\text { ISSN 1662-0631 } \\
\text { www.karger.com/crg }\end{array}$ \\
\hline
\end{tabular}

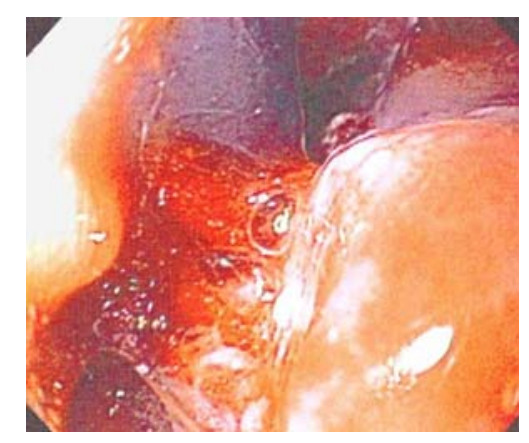

Fig. 1. Friable tumor on esophagogastroduodenoscopy $35 \mathrm{~cm}$ from the upper incisor.

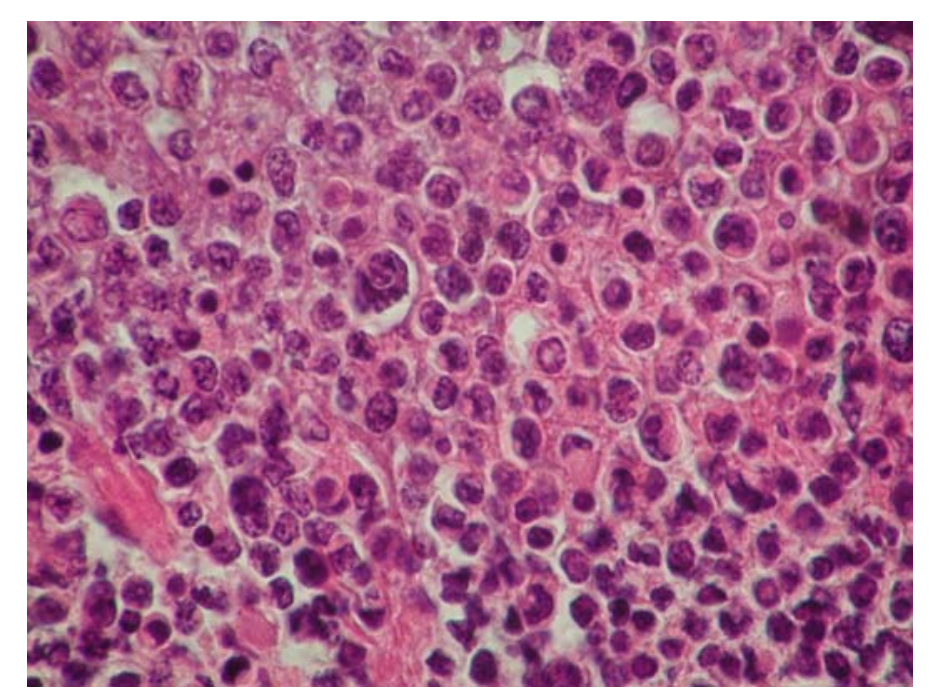

Fig. 2. Biopsy of esophageal mass demonstrating SCC at high power magnification. 


\begin{tabular}{c|l|l|l}
$\begin{aligned} \text { Case Reports in } \\
\text { Gastroenterology }\end{aligned}$ & $\begin{array}{l}\text { Case Rep Gastroenterol 2011;5:196-200 } \\
\text { DOI: 10.1159/000326958 }\end{array}$ & $\begin{array}{l}\text { Published online: } \\
\text { April 13, 2011 }\end{array}$ & $\begin{array}{l}\text { O 2011 S. Karger AG, Basel } \\
\text { ISSN 1662-0631 } \\
\text { www.karger.com/crg }\end{array}$ \\
\hline
\end{tabular}

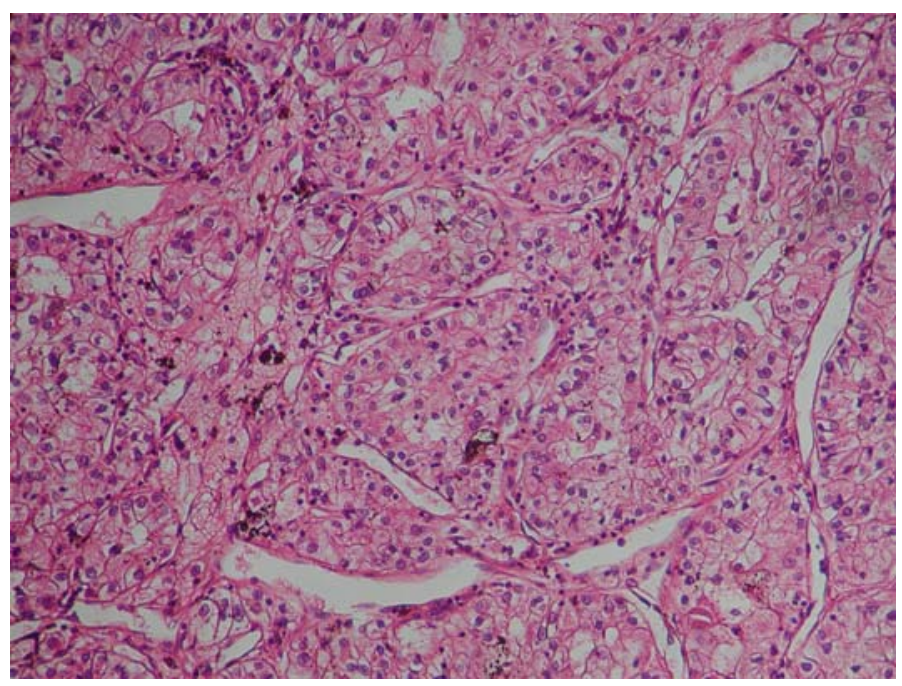

Fig. 3. Biopsy of renal mass demonstrating RCC.

\section{References}

$\checkmark 1$ De Hingh IHJT, Van Berge Henegouwen MI, Laguna Pes MP, Busch OR, Van Lanschot JJ: Synchronous esophageal and renal cell carcinoma: incidence and possible treatment strategies. Dig Surg 2008;25:27-31.

-2 Chack J, Finkelstein L, Marks B: Simultaneously renal cell carcinoma, adrenal adenoma, and carcinoma of the esophagus: report of a case. J Am Osteopath Assoc 1983;82:562-563.

3 Koike T, Honda H, Kimikawa M, et al: A case of double primary malignant neoplasm in the esophagus and kidney. Shokaki Naishikyo No Shinpo 1991;39:293-295.

4 Kobayashi S, Kabuto T, Doki Y, et al: Synchronous esophageal and renal cell carcinoma. Dis Esophagus 2000;13:305-310.

5 Kumagai Y, Kawano T, Nakajima Y, et al: Multiple primary cancers associated with esophageal carcinoma. Surg Today 2001;31:872-876.

6 Ku GY, Minsky BD, Rusch VW, Bains M, Kelsen DP, Ilson DH: Small cell carcinoma of the esophagus and gastroesophageal junction: review of the Memorial Sloan-Kettering experience. Ann Oncol 2008;19:533-537.

7 Lü JM, Liang J, Wang JW, et al: Clinical analysis of 126 patients with primary small cell carcinoma of the esophagus (in Chinese). Zhonghua Zhong Liu Za Zhi 2009;31:121-125.

8 Galanis E, Frytak S, Lloyd RV: Extrapulmonary small cell carcinoma. Cancer 1997;79:1729-1736.

-9 Hunt JD, van der Hel OL, McMillan GP, Bofetta P, Brennan P: Renal cell carcinoma in relation to cigarette smoking: meta-analysis of 24 studies. Int J Cancer 2005;114:101-108.

Author contribution: Parakkal Deepak contributed to collection of patient data, manuscript writing and the submission process. Radha Devi contributed to collection of patient data, manuscript writing and the submission process. Harikrishnan Pillai contributed to literature review, manuscript writing and the submission process. 